\title{
Promoting careers in health care for urban youth: What students, parents and educators can teach us
}

\author{
Lynne Holden ${ }^{\mathrm{a}, \mathrm{b}, *}$, Bernice Rumala $^{\mathrm{b}}$, Patricia Carson $^{\mathrm{c}}$ and Elliot Siegel ${ }^{\mathrm{d}}$ \\ ${ }^{a}$ Albert Einstein College of Medicine, Montefiore Medical Center, Department of Emergency Medicine, \\ Bronx, NY, USA \\ ${ }^{\mathrm{b}}$ Mentoring in Medicine, Inc., Bronx, NY, USA \\ ${ }^{\mathrm{c}}$ National Library of Medicine/National Institutes of Health, Bethesda, MD, USA \\ ${ }^{\mathrm{d}}$ Elliot Siegel Consulting, Bluffton, SC, USA
}

\begin{abstract}
There are many obstacles that urban youth experience in pursuing health careers, but the benefits of diversifying the classroom and workforce are clear. This is especially true today as educators and policymakers seek to enhance underrepresented minority students' access to health careers, and also achieve the health workforce needed to support the Affordable Care Act. The creation of student pipeline programs began more than 40 years ago, but success has been equivocal. In 2008, Mentoring in Medicine (MIM) conducted a research project to identify how students learn about health careers; develop strategies for an integrated, experiential learning program that encourages underrepresented minority students to pursue careers in health; and translate these into best practices for supporting students through their entire preparatory journey. Six focus groups were conducted with educators, students, and their parents. The inclusion of parents was unusual in studies of this kind. The outcome yielded important and surprising differences between student and parent knowledge, attitudes and beliefs. They informed our understanding of the factors that motivate and deter underrepresented minority students to pursue careers in health care. Specific programmatic strategies emerged that found their place in the subsequent development of new MIM programming that falls into the following three categories: community-based, school-based and Internet based. Best practices derived from these MIM programs are summarized and offered for consideration by other health career education program developers targeting underrepresented minority students, particularly those located in urban settings.
\end{abstract}

Keywords: Mentoring in Medicine (MIM), urban youth, health careers, underrepresented minority students, health workforce pipeline, STEM, youth development, parental influence, information and computer technology

\section{Introduction}

\subsection{The STEM challenge}

Nationally, there is a critical need to increase the number of American students pursuing careers that require preparation in Science, Technology, Engineering and Mathematics (STEM), including those in the health professions. It is necessary not only to address workforce needs, but also to keep America's competitive edge in the global knowledge economy [18]. The STEM deficit is due in part to the low

\footnotetext{
${ }^{*}$ Corresponding author: Lynne Holden, Albert Einstein College of Medicine, Montefiore Medical Center, Department of Emergency Medicine, Rosenthal SE-Rm 201, 111 East 210th Street, Bronx, NY 10467, USA. E-mail: holden@ medicalmentor.org.
} 
number of students in the U.S. who choose to pursue a career in this area. One potential solution to this problem is the creation and strengthening of pipeline programs for high school students and even middle school students to pursue undergraduate and graduate professional studies in STEM. For both social and pragmatic reasons it is vital that all students have equal access to STEM opportunities to enlarge the pool of students pursuing degrees in the field.

The National Task Force on Minority High Achievement identified the need for minorities to enter the field as an "American imperative". But currently access and success in the field is limited for underrepresented minority students due to the lack of academic preparation [7]. The creation of "pipeline" programs began more than 40 years ago [1] and has been demonstrated to increase minority access to health careers. The Meyerhoff Scholars Program for undergraduate African Americans in Baltimore [15] is an important proof of concept. Another is the National Institutes of Health's (NIH) Minority Opportunities in Research (MORE) programs that focuses on preparation for doctoral level research study [22].

But minority students are still lagging academically [20]. Despite the many programs that exist in the high school and college years to help augment the U.S. health care workforce, the data reveal that the increase in the diversity of the health care workforce has been slow. Only $24 \%$ of African American, Latinas/os and Native American students complete a science bachelor's degree in six years, compared to 40\% of White students [7]. Similarly, the Association of American Medical Colleges reported in 2012 that, in 15 years, the diversity of the applicant pool for health professional schools has not changed significantly. The percentage of medical school applicants who are African Americans, Hispanics and Native Americans are disproportionately below their make-up of the entire population and, combined, are less than fifteen percent [4].

\subsection{The need for minority health professionals}

The benefits in diversifying the classroom and workforce are clear. Racial diversity among students in their medical education can enhance the educational experience for all students [23]. Moreover, racial and ethnic minority health care providers are more likely to serve minority and medically underserved communities, increasing access to care among these populations [5]. McDougle et al. [16] found that premedical post-baccalaureate training programs that prepared underrepresented minority or disadvantaged students also decreased health disparities, as graduates have an increased likelihood of providing care for the medically indigent and the poor. Other studies have found that minority patients were more likely to follow the physician's advice if the physician was from a minority group [6]. Not only is the educational disparity being addressed when underrepresented minority students are trained in health careers, but we are also closing the gap in health disparities.

The need for qualified physicians who are culturally competent to treat minority patients is becoming greater as the minority population continues to grow [7]. Additionally, the Patient Protection and Affordable Care Act (Public Law 111-148) [21] is expected to expand insurance coverage for low income, uninsured patents, many of whom will also be minorities. A concern is that there will not be enough physicians and other health care providers willing and able to care for them [14].

For these reasons it is important that students be as prepared as possible for college level work not only through K-12 education, but also through enrichment and after school programs [19] that inspire youth to pursue a career in the health care field. But not all pipeline programs have been successful. Much can be learned from programs that do not work out entirely as intended. A review of selected programs funded by the Robert Wood Johnson Foundation [13], Isaacs and Colby concluded that the reasons can be many including flawed strategy or design, a difficult environmental context, or faulty execution. 
Anticipating problems in advance, learning from others' experiences, putting in place a planning and evaluation strategy that assesses impact and generating lessons learned can all increase the probability of a program's success. It can be hypothesized that having a sound understanding of the target audience's attitudes, beliefs, perceptions and expectations for success is a necessary starting point for successful program development.

\subsection{Mentoring in Medicine (MIM), Inc.}

MIM is a 501(c)3 non-profit organization founded in 2006 by three emergency medicine physicians. MIM seeks to develop non-traditional educational experiences that (1) foster underrepresented minority student interest in the health professions; (2) contribute to the societal goal of increasing workforce diversity; and thereby, (3) improve health services and patient outcomes in underserved minority communities. The core goal is to turn dreamers into health professionals through academic enrichment, leadership development, civic engagement, and mentoring. MIM is based in New York City and has local activities in the metropolitan Washington, DC area, New Orleans, Philadelphia, Detroit and Atlanta. The focus is on urban youth.

George-Jackson and Lictenberger [9] concluded that programs that provide hands-on experience and access to positive role models that shape student perceptions and enhance student confidence, are most successful in making an impact in a student's career decision. Since the inception of MIM, the following interventions have been undertaken to promote learning: individual mentoring by health professionals; conferences and workshops for educators, students and parents; career exhibitions; interactive in-class exercises/games; field trips; hands-on biology and anatomy labs; formal in-class and after-school instruction in healthy living; special instruction in the biological sciences and related health careers; strengthening study and test preparation skills and confidence building; and most recently virtual interactive e-learning classes and webinars offered over the Internet. These programs target learners at all grade levels, encompassing elementary, middle, high school, college and professional students. They focus on health careers requiring baccalaureate and advanced professional training (e.g., medicine, nursing, dentistry), as well as careers in the ancillary health professions (e.g., laboratory technician, dental hygienist) in which a two-year program of study, or a certificate of proficiency is required. MIM is particularly relevant to addressing, within the larger STEM challenge, the lack of underrepresented minority participation in the biological sciences and the health care professions that account for many of the fastest growing occupations over the coming decade [8].

\subsection{Study goals}

In 2008, the National Library of Medicine (NLM) supported a study by MIM. The project had as its goals: (1) research how urban youth comprising primarily underrepresented minority students learn about health careers; (2) develop strategies for an integrated, experiential learning program that encourages underrepresented minority students to pursue careers in health and (3) identify best practices for supporting students through their entire preparatory journey.

This paper reports on those aspects of a series of face-to-face focus groups with students, parents, and educators to identify strategies for motivating students to learn about and pursue health care careers. The inclusion of parents as key participants of the study is unusual. It separates this research from other efforts that typically target only students and educators. Reported also is the implementation of identified best practices that in the ensuing period of time have been incorporated in the development of MIM's educational programming. 


\section{Methods}

As a qualitative research methodology, focus groups seek to develop insight and direction rather than quantitatively precise measures. The value of focus groups include their ability to provide unfiltered comments from a segment of the targeted audience, and for decision-makers to gain insight into the beliefs, attitudes, and perceptions expressed through these comments. While the data cannot be projected to a universe of similar respondents as may be possible in a scientifically derived sample survey, the method allows for probing of respondents' views on specific questions in addition to an ability to observe the extent to which such views are held and supported by other participants in the focus group.

\subsection{Participants}

Four 90-minute focus groups were conducted on October 2, 2008 at the New York Academy of Medicine, located in New York City, in an evening program for local high school counselors, teachers, principals, and college students. Participants were invited by MIM based on their local experience working with high school students, specifically underrepresented minority groups. Participants were selected based on their occupation (i.e., teacher or administrator), and each group had a mix of participants in terms of age, gender, and high school affiliation. A second focus group session was conducted at a New York City high school on November 22, 2008. The Frederick Douglas Academy, site of an all day "Yes, I Can be a Health Professional" event hosted by MIM, also included on its program two invitational 90-minute focus groups; one comprised of high school students and a second with the parents of these students. It should be noted that these participants were predisposed towards learning about careers in the health professions, by virtue of their attendance at this MIM outreach event at which the focus groups were organized. In total, there were six focus groups studied; with a total of 45 persons in the first session, and 10 persons in each of the second session groups. There was no formal consent process. The agreement to participate in the focus groups was taken to indicate implied consent. The names of the participants were not recorded. The participants knew that notes would be taken on the discussions and that the content would be summarized and presented to the National Library of Medicine and at other professional forums.

\subsection{Procedures}

Focus groups were asked to discuss three topics: (1) resources, influences and motivation in pursuing a career in the health field; (2) obstacles that underrepresented minority students face in their pursuit; and (3) strategies to effectively reach out to high school students and encourage them to consider a health care career. Facilitators of the focus groups were trained by an expert in qualitative methods with a doctorate in Educational Administration and Policy Analysis. Participant responses were recorded by trained graduate students who analyzed the notes for common themes concerning, for example, the ways that high school students choose and think about a health care career, barriers to making those choices, and strategies to promote health careers. Two trained analysts each reviewed the notes and developed a coding scheme based on the three topics that were the focus of the study. Themes were identified separately and were then compared. The two analysts discussed differences. When consensus could not be reached, differences were adjudicated by the principal investigators. 


\section{Results}

An enumeration of all the identified obstacles faced by underrepresented minority students, parents, and educators is shown in Table 1.

Upon further analysis, important insights were identified that were common to all focus group participant categories and others that underscored interesting differences, especially with respect to students and their parents that have implications for MIM programming.

Focus group findings:

(1) Most high schools students do not think about careers until the end of their high school experience. The few who do decide early report that their decision is usually due to a "defining moment" that occurs when the student has had an experience or exposure to someone in that field.

(2) Health care is not a popular field among students for many reasons: many have a negative image due to their own lack of experiences, or experiences that are negative; students do not have the knowledge either of the variety of health care professions; and health care does not have the status other fields have, such as athletics or entertainment.

Table 1

Perceived obstacles to choosing health careers

\begin{tabular}{|c|c|c|}
\hline Students & Parents & Educators \\
\hline $\begin{array}{l}\text { Negative image of science and math, } \\
\text { too difficult, boring, too much work }\end{array}$ & Not knowledgeable about career options & $\begin{array}{l}\text { Schools do not have resources to know } \\
\text { of events, opportunities for students }\end{array}$ \\
\hline $\begin{array}{l}\text { Lack of self-confidence to do well } \\
\text { academically }\end{array}$ & $\begin{array}{l}\text { Limited resources and time to provide } \\
\text { experiences for students or to push for } \\
\text { more opportunities through schools, } \\
\text { churches, community centers }\end{array}$ & $\begin{array}{l}\text { No central location to find information } \\
\text { about health careers or career options } \\
\text { and teaching materials }\end{array}$ \\
\hline $\begin{array}{l}\text { Lack of adequate preparation for } \\
\text { college programs because career } \\
\text { decisions are made too late }\end{array}$ & $\begin{array}{l}\text { Lack of information about possible } \\
\text { scholarship information to assist with } \\
\text { studies }\end{array}$ & $\begin{array}{l}\text { Lack of role models that look like } \\
\text { students to tap as mentors or speakers to } \\
\text { motivate students }\end{array}$ \\
\hline Lack of knowledge about financial aid & $\begin{array}{l}\text { Unable to pay fees for programs and } \\
\text { internships }\end{array}$ & $\begin{array}{l}\text { Lack of resources to take trips, organize } \\
\text { internships or other programs }\end{array}$ \\
\hline $\begin{array}{l}\text { Not enough role models that look like } \\
\text { them }\end{array}$ & $\begin{array}{l}\text { Difficult with paperwork to apply for } \\
\text { programs and financial aid }\end{array}$ & $\begin{array}{l}\text { Lack of local resources to organize } \\
\text { internships and other activities }\end{array}$ \\
\hline $\begin{array}{l}\text { Limited positive views of health care } \\
\text { professionals }\end{array}$ & & $\begin{array}{l}\text { Teachers often receive little or no } \\
\text { incentive to develop or lead programs }\end{array}$ \\
\hline $\begin{array}{l}\text { Extra programs conflict with need to } \\
\text { work after school work schedules }\end{array}$ & & $\begin{array}{l}\text { Lack of skilled and motivated science } \\
\text { teachers to engage students }\end{array}$ \\
\hline $\begin{array}{l}\text { Stigma about some professions for } \\
\text { males, such as nursing }\end{array}$ & & $\begin{array}{l}\text { Inability to adequately prepare students } \\
\text { to succeed in science and math courses } \\
\text { in college }\end{array}$ \\
\hline $\begin{array}{l}\text { Stigma for girls about becoming too } \\
\text { smart and what happens, "when you are } \\
\text { smarter than the boys?" }\end{array}$ & & $\begin{array}{l}\text { Schools focus on the current life of the } \\
\text { student and not their future life/career }\end{array}$ \\
\hline \multicolumn{3}{|l|}{ Health care careers not seen as "cool" } \\
\hline \multicolumn{3}{|l|}{$\begin{array}{l}\text { Lack peer support to pursue health care } \\
\text { careers }\end{array}$} \\
\hline $\begin{array}{l}\text { Going against the norm by being the } \\
\text { first to go into a healthcare field or to } \\
\text { college }\end{array}$ & & \\
\hline
\end{tabular}


(3) Students face many challenges if they do want to enter the health care field. Many do not have the prerequisites or skills necessary to do well in college math and science and often lack the self-confidence to go into a field that generally does not reflect their background.

(4) Parents have a significant impact in the career their children chose, but often lack knowledge themselves about the variety of health care professions. In addition, there is an image that education and training will be expensive and they do not have the time and resources to research financial assistance programs, internships, or other program that might help their children succeed in the health care field.

(5) Schools and teachers also struggle with promoting health care careers among their students. Teachers lack the resources to put together speakers, activities, or internships in the health care field. Similarly, many schools lack the science and math resources to provide students a strong background in these subjects.

(6) Overwhelmingly, the participants favored hands-on activities to generate student interest. Incentives and other rewards would increase participation.

(7) Participants strongly supported comprehensive programs that start early and take the student from middle school up through college. These programs would provide moral support, a variety of learning experiences (such as leadership training), and financial help at each point.

(8) A centralized location for resources was highly supported, as well as the creation of regional networks to connect the resources of local schools, hospitals and others.

\section{Findings that differed in parent and student focus groups:}

(1) Who has the most influence? There were differing views on who/what influences students' career choices. Students said their friends were the primary influence on them, while parents thought they were. (Those days seem to be long gone according to students.) Interestingly, teachers and educational administrators thought that they and the parents were the most influential in students' lives.

(2) The 'cool' factor. Students said that organizations and schools need to do a better job to "make sure kids know its health care careers that are really cool". Surprisingly, parents seem to think health care careers were viewed as less cool to kids than the kids indicated. No doubt, there is a cool factor issue, as it came up in every focus group, but perhaps not as significant as parents (and the teachers at the other focus groups) seem to indicate.

(3) A lack of confidence. Parents and teachers indicated that they thought one of the obstacles students would face if they wanted to go into the health care field was being labeled a "nerd", and this would have negative social consequences for students. Students on the other hand, mentioned their fear of not being able to live up to their potential more than their fear of being labeled as "uncool" or a nerd among their peers.

(4) Negative health event as motivator. Students mentioned that they were motivated by negative events, such as an uncle dying of a heart attack. Parents did not list this type of event as something that would motivate students to enter the health care field. Instead, parents, as well as teachers, indicated that negative events would dissuade students listed these types of events as reasons why students do not choose to go into health care.

(5) Influence of the Internet. Another area in which there was disagreement was in how influential the Internet was. Parents did not think students used it to find out information about careers, but students listed it as one of the primary ways they learned about careers. 
(6) Money as a motivator and a disincentive. Both parents and students agreed, although students more so, that money was a big motivator for choosing a specific career. However, parents seemed to think it was their primary responsibility to look for financial aid for their student, and had many suggestions about how better to disseminate information to them on this topic. But, many parents felt overwhelmed with the possible financial burden and lacking in their knowledge of the opportunities and assistance that could assist them.

(7) What programs are needed to motivate students? Parents promoted ideas such as health care fairs, speakers and such, but students echoed what teachers and administrators said, the most effective program would be one that has different dimensions to it (i.e. hands-on with computer) and longlasting. Students indicated, as did teachers, that one-time interactive activities do not have a lasting impact on students.

\section{Discussion}

The focus group findings proved very useful for meeting the study goal of developing ideas for an integrated, experiential learning program that encourages underrepresented minority students to pursue careers in health care. We looked at those strategies that emerged, examined how they could be defined as best practices and translated into programmatic elements that shaped MIM initiatives in the ensuing years. (Table 2.)

Focus group participants had a lot to say about strategies that they thought would work well with students, and others that they felt had failed over the years. They indicated that historically many of the programs and activities have been "one-shot" experiences. This would include a career day event once a year, special speakers, or limited time only after school activity. These activities, participants noted, were easily forgotten by students and had little impact on students. While some indicated they could be a good first step, it was thought by many that there needed to be follow-up to maintain student interest and turn that interest into participation.

Consequently, many participants felt that the best approach would be one that was comprehensive and long-term. It would be comprehensive in that it would include a wide range of activities to engage a wider variety of students, and have elements that include parents and teachers, and would actively engage students as well. A fundamental component is exposing students to health careers, through professionals, the Internet and fact-to-face experiences. In addition, the topics covered would include everything from parent/student workshops on finding financial aid, to role-playing with students about how to conduct a college interview, to ensuring students have direct mentoring by a health care professional that they could model themselves after.

These elements would also have a long-term quality to them and begin when students are in middle school so they can be better prepared by the time they finish high school. A successful program would also follow through into college so students do not suddenly lose the support and mentors during the process.

In addition, participants indicated that the image of the health care field needs to change. This change may include advertising that features celebrities, as it is felt that high schools students are influenced by them; educating the health care community to view underrepresented minority students as possible future health care professionals; and showing students the variety of positions available and the good lifestyle it can provide students. 
Table 2

Strategies to effectively promote health care careers

\begin{tabular}{|c|c|}
\hline \multicolumn{2}{|c|}{ Strategies } \\
\hline Most effective & Least effective \\
\hline $\begin{array}{l}\text { Direct and positive exposure to minority role models in health } \\
\text { care fields, with personal stories of those, like them, who are } \\
\text { in the field and have "made it" }\end{array}$ & One time only models that do not stay with the student \\
\hline $\begin{array}{l}\text { Outline for students the various positions associated with the } \\
\text { health care field, the salaries attached to each position, and } \\
\text { the positive role it plays in society }\end{array}$ & $\begin{array}{l}\text { Text information that is not coupled with a face-to-face or } \\
\text { hands-on experience }\end{array}$ \\
\hline $\begin{array}{l}\text { Develop programs that hook students early and stay with } \\
\text { them so they do not lose their drive and support }\end{array}$ & Activities where they just read materials to learn something \\
\hline $\begin{array}{l}\text { Internet related activities that can connect students with } \\
\text { others and provide resources }\end{array}$ & $\begin{array}{l}\text { Experiences that require students step outside of their comfort } \\
\text { zone and do something new without guidance or support to } \\
\text { accompany it }\end{array}$ \\
\hline $\begin{array}{l}\text { Provide hands-on and long-term experiences. Students need } \\
\text { to feel "useful" }\end{array}$ & $\begin{array}{l}\text { Activities that do not engage the student or put some of the } \\
\text { responsibility on them for finding information or } \\
\text { participating; students need to own the experience }\end{array}$ \\
\hline \multicolumn{2}{|l|}{$\begin{array}{l}\text { Students will continue with program if there is a relatively } \\
\text { short-term reward, such as stipend or trip associated with } \\
\text { participation, otherwise there is strong competition for the } \\
\text { students' time }\end{array}$} \\
\hline \multicolumn{2}{|l|}{$\begin{array}{l}\text { Get parents and teachers involved by providing workshops or } \\
\text { other resources for them - everyone needs to be a part of the } \\
\text { process and a stakeholder to support and motivate the student }\end{array}$} \\
\hline \multicolumn{2}{|l|}{$\begin{array}{l}\text { Make science "cool again." Schools need more interactive } \\
\text { and captivating science labs with speakers who connect it to } \\
\text { interesting real life stories }\end{array}$} \\
\hline \multicolumn{2}{|l|}{$\begin{array}{l}\text { Develop programs that include leadership and life skills } \\
\text { training }\end{array}$} \\
\hline \multicolumn{2}{|l|}{$\begin{array}{l}\text { Connect health care to their interests, such as sports with } \\
\text { careers in sports medicine }\end{array}$} \\
\hline \multicolumn{2}{|l|}{$\begin{array}{l}\text { Help students connect the dots by asking them to identify the } \\
\text { lifestyle they want, what professions can provide that, and } \\
\text { what they need to do now to attain it }\end{array}$} \\
\hline $\begin{array}{l}\text { Work with local community colleges to better prepare } \\
\text { students for college life and courses }\end{array}$ & \\
\hline
\end{tabular}

\section{Implementation of best practices in MIM programming}

\subsection{Community-based}

Yes, I Can be a Health Care Professional is a one-day program now in its 8th year that attracts up to 2,500 students and their parents throughout the metropolitan New York City area. But it is far from being a one-shot experience or a health fair. It lays the foundation for MIM's follow-up virtual programmingthe Virtual Science Camp. Targeted students range from the middle school grades through college; although younger elementary school age siblings are commonplace in the audience. They are treated to dynamic and inspiring life storytelling by diverse, successful health professionals who have overcome their own personal challenges and present positive role models who students can relate to. A mixture of entertainment and education engage and motivate students and parents alike, and are an entry point to more than a dozen rotational hands-on participatory demonstration classes that follow. Donning a surgi- 
cal gown, learning about the skin and suturing a laceration on a pig's foot is just one example. Exhibit tables fill the entire floor space in the high school gym where the program takes place. They provide opportunities for students to interact with physicians, dentists, pharmacists, emergency services personnel, health science librarians, and a wide range of practicing ancillary health professionals through both individual conversation, and career specific activities. Students are encouraged to further explore career options, requirements and funding opportunities using web based resources and by participating in MIM hosted webinars, social media, and email newsletters.

\subsection{School based}

After School Program (ASP) is taught in spring and fall semesters at a half-dozen high schools in New York City's Harlem and the Bronx. It has been offered more than 45 times since 2009 and approximately 800 African American and Hispanic students have been exposed to a specially constructed curriculum that is taught by college and graduate students, supervised by science teachers who receive compensation, and volunteer health professionals who impart their expertise and serve as positive role models. The ASP curriculum covers the body's 11 organ systems, introduces students to a variety of health care careers that focus on each system, and the diseases and conditions that can affect each. Organized field trips to area hospitals, health professional schools and laboratories are very popular. Course evaluations and pre- and post-measures of knowledge gain are conducted at the start and conclusion of each semester [2]. School principals, teachers, students, and parents are enthusiastic about the program and its potential impact on student academic success and future career choices in the health care professions. A companion course, the In-School Program (ISP) has been offered as a for-credit elective since 2012. In 2013, approximately 121 students completed the two semester-long classes [3].

\subsection{Internet based}

Virtual Science Camp (VSC) for urban youth offered for the first time during the summer of 2012 and is a two-week enrichment course in the biological sciences. The VSC employs a video streaming service enabling lectures to be broadcast live in real-time from a MIM studio. Students log-in remotely from their own computers and can interactively communicate with the instructors and fellow students via chat and email. Demonstrations are a staple course offering, individual and group student course projects are a part of the evaluation, and daily journaling encourages student engagement. VSC is offered interactively as a cost-free, synchronous e-learning experience over the Internet. Intended to reach underrepresented minority high school students, it seeks to overcome negative images of science and promotes healthy living. It has the potential to introduce more students to MIM offerings than is possible in the ASP where there may be conflicts with after school work schedules; and the ISP courses where enrollments are very limited. A total of 55 students successfully completed the course requirements in 2013 and 142 in 2014 [11].

Medical Pathway Program (MPP) is a holistic 20-week intensive boot camp that prepares premedical students for the journey to medical school and the achievement of their dream of becoming a physician. Students work with an MCAT test prep coach, a learning specialist, an acting coach, a mental performance coach, and receive advising during the medical school application process, including mock interviewing. Mentoring is both in-person and virtual. Offered since 2009, MPP has in the past two years seen an $87 \%$ acceptance rate of students who apply to medical school, and an increase of 8-10 points on MCAT scores. 
Interactive Webinar Series is the most recent MIM program offering to take advantage of the lessons learned in the focus group sessions with students and parents. Those focus groups revealed important insights regarding parents' candid concerns about their students' pursuit of a career in health care, and how they may be encouraged to be more supportive and enabling. Sensitized to these issues, MIM looked for and found many of the same concerns expressed as recurrent themes in evaluations of the after school program and the in-class elective. In 2014, MIM initiated a 6-session program of interactive online Webinars for parents and students taught by local experts in the New York City area. Specific topics addressed were the college admissions process; locating financial resources and applying for financial aid; SAT preparation; applying to medical school; and free resources available elsewhere on test taking, scholarships, and summer enrichment programs. Sessions were one-hour in length, costfree, and required registration. They were also accessible voice-only via telephone dial-up by parents and students who lacked convenient access to a computer with a broadband Internet connection at the specific time a webinar was offered. A series of podcast recordings of the sessions was also posted on the MIM website for downloading and later listening. Webinar participants logged-on or called-in from locations throughout the U.S. either listening alone or together as parent-student pairs. They were able to be recognized by the moderator and could ask questions that were answered in real time during the Webinar, or later offline. An average of 25-100 participants per session was documented in this initial pilot offering. In recent years, we have seen significant advances in accessible and affordable desktop and mobile computer technology that offers cost-effective and democratic means to disseminate factual knowledge and improve understanding. Webinar that are targeted to specific audiences and their information needs, combined with more generic web-based information resources, can help inform and ameliorate parental concerns regarding such critical issues as education funding. Often that may spell the difference in a student's motivation to successfully pursue a health care career or not, given the overriding influence that parents have on their children's career choices.

MIM programming incorporates important elements that can serve as best practices for other health career-oriented educational interventions with underrepresented minority students in urban settings: (1) Know and understand all aspects your target population, including their attitudes, beliefs, and concerns; (2) Address disincentives, such as family financial limitations, peer pressures, and the lack of positive role models; (3) Develop programming that is comprehensive, long-term, and participatory; (4) Develop programming that is age and grade appropriate, encompassing and reinforcing the journey that students make from middle school to high school, through community and four year college, and enrollment by some in graduate professional school; (5) Venture outside the traditional classroom to offer after school courses, and experiment with information and computer technologies that support interactive virtual e-learning; and (6) Provide individual and group mentoring whenever possible, including exercises that build self-confidence and enhance test-taking skills.

\section{Summary and conclusions}

Workforce pipeline programs that are intended to increase the number of American students pursuing careers in STEM generally, and the health care professions in particular, have thus far achieved equivocal results. This is particularly challenging for minority students whose presence in the health care workforce can be expected to improve access to care in medically underserved communities, while also enhancing job prospects for a population whose career aspirations are subject to considerable obstacles relating to entrenched stereotypes, and the resource limitations of local school systems and family fi- 
nances. Successful pipeline programs should begin with a sound understanding of the target audience's attitudes, beliefs, and perceptions for achieving the dream of becoming a health care professional.

Focus groups conducted with educators, students and their parents revealed significant deficits in knowledge about the variety of health care careers that can be pursued at different educational levels; students' math and science skills; student self-confidence; and knowledge about financial aid possibilities. All are subject to remediation. Additionally, valuable insight was gained in understanding what program elements can be most effective in motivating and sustaining student interest and participation. These call for longer-term, experiential hands-on exposure; lively and entertaining components that incorporate song, dance, and games; engaging demonstrations; guest speakers who are role models and can excite the imagination; use of new information and computer technologies for e-learning and social networking; and personalized group and individual mentoring that builds self-confidence, enhances interpersonal and test-taking skills. These strategies have been translated into best practices and successfully incorporated by MIM into new and innovative programming that is grade-appropriate for middle, high school, and college students, and their parents. Courses and other educational interventions are offered at varying times of the day and year: after school, in-class, and in virtual time and space to accommodate students' schedules and preferences. All programs are evaluated and the performance of students is bench-marked. In all cases, the close support of school administrators and science teachers has proven to be essential, and has resulted in adherence to the high educational standards of the schools and the communities they serve.

The development of a long-term student tracking project is underway. This effort will go beyond the present focus of documenting as dependent measures student participation and completion of MIM course work, including measurement of new knowledge gained and attitudes changed. New evaluation goals will focus on identifying and documenting the students' pursuit of additional education and training in a post-high school course of study leading to a degree or certificate; successful completion of that course of study; and attainment of a professional career in health care.

\section{Acknowledgements}

MIM would like to sincerely thank Donald Lindberg, MD, Director of the National Library of Medicine for his support and dedication to helping improve health literacy for everyone. We would also like to express our appreciation to Wallace Berger, PhD, LightShift Associates, Inc. for his evaluation and contribution to the growth of the MIM programs. A very special thank you to Donald King, MD, Richard Crane Professor of Pathology, University of Chicago (retired) who has invested his time and energy into helping to develop MIM programs. MIM would like to sincerely thank Kim D'Abreu, MPH, senior vice-president of Access, Diversity and Inclusion, Policy Center, American Dental Education Association, Susan Sandmeyer (Retired Program Director) and Henryne Tobias (Program Coordinator) of the organization's web-learning platform ExploreHealthCareers.org for their assistance with the project.

This work was supported by contract HHSN276201300011C with the National Library of Medicine/ National Institutes of Health. The study was approved by the Albert Einstein College of Medicine Institutional Review Board.

\section{References}

[1] S.S. Bergen, Underrepresented minorities in medicine, JAMA 284(9) (2000), 1085-1092.

[2] W.G. Berger, Evaluation Report for Spring 2013 After School Program. Mentoring in Medicine Internal Report, July 5, 2013. (Available from the primary author.) 
[3] W.G. Berger, Evaluation Report for Spring 2013 In-Class Program. Mentoring in Medicine Internal Report, July 9, 2013. (Available from the primary author.)

[4] L. Castillo-Page, Diversity in the Physician Workforce: Facts \& Figures 2010, Association of American Medical Colleges, Diversity Policy and Programs, 2010.

[5] Committee on Institutional and Policy-Level Strategies for Increasing the Diversity of the U.S. Health Care Workforce, Board on Health Sciences Policy, the Nation's Compelling Interest: Ensuring Diversity in the Health Care Workforce, Institute of Medicine, National Academies Press, Washington, DC, 2004.

[6] L.A. Cooper and N.R. Powe, Disparities in patient experiences, health care processes, and outcomes: the role of patientprovider racial, ethnic, and language concordance, The Commonwealth Fund. 2004 July, 1-29.

[7] Council on Graduate Medical Education, Seventeenth Report Minorities in Medicine: An Ethnic and Cultural Challenge for Physician Training, an Update, U.S. Department of Health and Human Services, 2005.

[8] Department of Labor, The STEM workforce challenge: The role of the public workforce system in a national solution for a competitive science, technology, engineering, and mathematics (STEM) workforce, Washington, DC, 2007.

[9] C.E. George-Jackson and E.J. Lichtenberger, College Confidence: How Sure High School Students Are of Their Future Majors, Illinois Education Research Council, 2012.

[10] L. Holden, A pilot after school program in human biology, health disparities, and biomedical careers, in: Ninth Annual AAMC Physician Workforce Research Conference, Alexandria, VA, 2-3 May 2013.

[11] L. Holden, A. Morrison, W. Berger and E. Siegel, E-learning in a virtual science camp for urban youth, Information Services and Use 33 (2013), 299-308.

[12] S. Hurtado, N.L. Cabrera, M.H. Lin, L. Arellano and L.L. Espinosa, Diversifying science: Underrepresented student experiences in structured research programs, Research in Higher Education 50(2) (2009), 189-214.

[13] S.L. Isaacs and D.C. Colby, Good ideas at the time: learning from programs that did not work out as expected, in: To Improve Health and Health Care, L. Stephen, Isaacs and D.C. Colby, eds, Robert Wood Johnson Foundation, 2009.

[14] L. Marrast, L. Zallman, S. Woolhandler, D. Bor and D. McCormack, Minority physicians' role in the care of underserved patients: Diversifying the physician workforce may be key in addressing health disparities, JAMA Internal Medicine 174(2) (2014), 289-291.

[15] K.I. Maton, F.A. Hrabowski and C.L. Schmitt, African American college students excelling in the sciences: College and post college outcomes in the Meyerhoff Scholars Program, Journal of Research in Science Teaching 37(7) (2000), $629-654$.

[16] L. McDougle, Survey of care for the underserved: a control group study of practicing physicians who were graduates of The Ohio State University College of Medicine premedical postbaccalaureate training program, Academic Medicine $\mathbf{8 5}$ (1) (2010), 36-40.

[17] National Library of Medicine, Report by the American Dental Education Association; ExploreHealthCareers.org; and Mentoring in Medicine, Department of Health and Human Services, Bethesda, MD, December 2008.

[18] National Research Council, Successful STEM education: A workshop summary, The National Academies Press, Washington, DC, 2011.

[19] National Task Force on Minority High Achievement, Reaching the top: A report of the national task force on minority high achievement, The College Board, New York, 1999.

[20] Office of Minority Health, Bureau of Health Professions, Health Resources and Services Administration, Pipeline programs to improve racial and ethnic diversity in the health professions: an inventory of federal programs, assessment of evaluation approaches, and critical review of the research literature, Washington, DC, 2009.

[21] Patient Affordability and Care Act, Public Law 111-148, March 23, 2010.

[22] S.P. Slovacek, J.C. Whittinghill, S. Tucker, A.R. Peterfreund, K.A. Rath, G.D. Kuehn and Y.G. Reinke, Minority students severely underrepresented in science, technology, engineering and math, Journal of STEM Education 12 (2011), 1-2, $5-16$.

[23] D.K. Whitla, G. Orfield, W. Silen, C. Teperow, C. Howard and J. Reede, Educational benefits of diversity in medical school: a survey of students, Academic Medicine 78(5) (2003), 460-466. 